\title{
EFEITO DA TEMPERATURA DE RECOZIMENTO NAS PROPRIEDADES MECÂNICAS E NA MICROESTRUTURA DE UM AÇO COM ALTO TEOR DE Mn LAMINADO A FRIO*
}

Julio Cezar de Sousa Zorzi ${ }^{1}$
Túlio Magno Füzessy de Melo
Dagoberto Brandão Santos

\section{Resumo}

Aços com teor de Mn entre 15\% e 30\% apresentam ductilidade excepcionalmente alta para sua elevada resistência mecânica, devido à ocorrência de transformação de fases (efeito TRIP) e/ou à formação de maclas de deformação (efeito TWIP) na microestrutura predominantemente austenítica. A adição de $\mathrm{Mn}$ ajuda a manter a austenita até a temperatura ambiente, evitando a sua decomposição após o recozimento aplicado depois da laminação a frio. O objetivo desse estudo foi avaliar o efeito da temperatura de recozimento na microestrutura e nos valores de propriedades mecânicas de um aço com 17\% de Mn, por meio de simulações piloto das etapas de processamento industrial utilizando dilatômetro e simulador termomecânico do Centro de Pesquisa da Usiminas. Observou-se que o aumento na temperatura de encharque durante o ciclo térmico de recozimento contínuo promoveu a reversão completa da martensita a' para austenita. Além disso, a alteração desse parâmetro praticamente não afetou o limite de resistência e o alongamento total do aço, embora tenha reduzido significativamente o limite de escoamento.

Palavras-chave: Alto Mn; Efeito TRIP; Efeito TWIP; Aço austenítico.

\section{EFFECT OF ANNEALING TEMPERATURE ON MICROSTRUCTURE AND MECHANICAL PROPERTIES OF A STEEL WITH HIGH CONTENT OF MN COLD ROLLED}

\section{Abstract}

Steels containing Mn between $15 \%$ and $30 \%$ have high ductility and high mechanical strength, due to either martensitic transformation (TRIP effect) and/or mechanical twinning (TWIP effect) in the austenitic microstructure. The austenite phase stability to room temperature is related with addition of $\mathrm{Mn}$, which avoid the austenite phase decomposition after annealing step. The objective of this study was to evaluate the effect of annealing temperature on the microstructure and mechanical properties in a steel containing $17 \% \mathrm{Mn}$, through simulations of the industrial processing steps using dilatometer and thermo mechanical simulator of the Usiminas Research Center. It was observed that the increase in the soaking temperature during continuous annealing heat cycle promoted the complete reversion of $\alpha^{\prime}$ martensite to austenite. Moreover, the change of this parameter did not affect the tensile strength and total elongation of steel, although the yield strength is significantly reduced.

Keywords: High Mn; TRIP effect; TWIP effect; Austenitic steel.

Engenheiro Mecânico, Centro de Pesquisa e Desenvolvimento, Usiminas, Ipatinga, MG.

Engenheiro Mecânico, M.Sc., Dr.-Ing., Centro de Pesquisa e Desenvolvimento, Usiminas, Ipatinga, MG.

3 Professor Associado, Departamento de Engenharia Metalúrgica e de Materiais, Universidade Federal de Minas Gerais - UFMG, Belo horizonte, MG.

* Contribuição técnica ao $51^{\circ}$ Seminário de Laminação - Processos e Produtos Laminados e Revestidos, 28 a 31 de outubro de 2014, Foz do Iguaçu, PR, Brasil. 


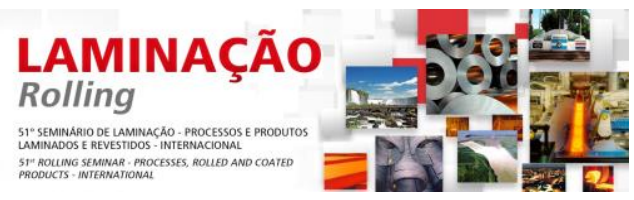

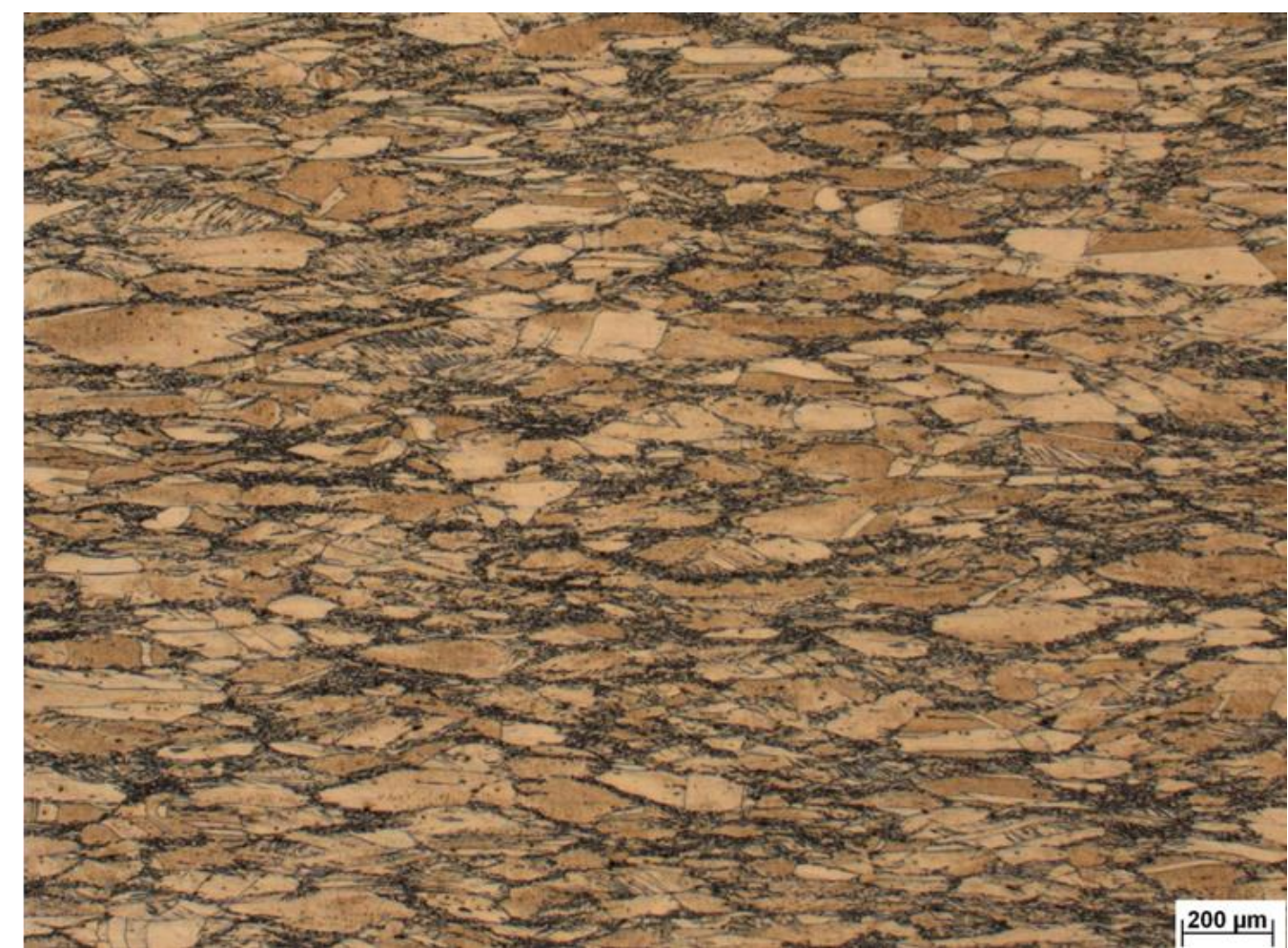

Figura 3-Aspecto microestrutural do material na condição de laminado a quente, observado por microscopia óptica. Ampliação original 50X.

Além da austenita, também estão presentes na microestrutura a martensita $\alpha$ e a martensita $\varepsilon$, como mostra o difratograma da figura 4. A martensita $\varepsilon$ apresenta-se com aspecto de placas finas paralelas, que se formam no interior dos grãos austeníticos e são delimitadas pelos contornos de grão. A martensita $\alpha$ ' pode ser formada também a partir da austenita ou na interseção entre as placas de martensita $\varepsilon$ com a austenita [9]. A quantificação das fases identificadas no difratograma da figura 4 revelou que a microestrutura do aço é composta por $91,6 \%$ de austenita, $7,7 \%$ de martensita $\alpha^{\prime}$ e $0,7 \%$ de martensita $\varepsilon$.

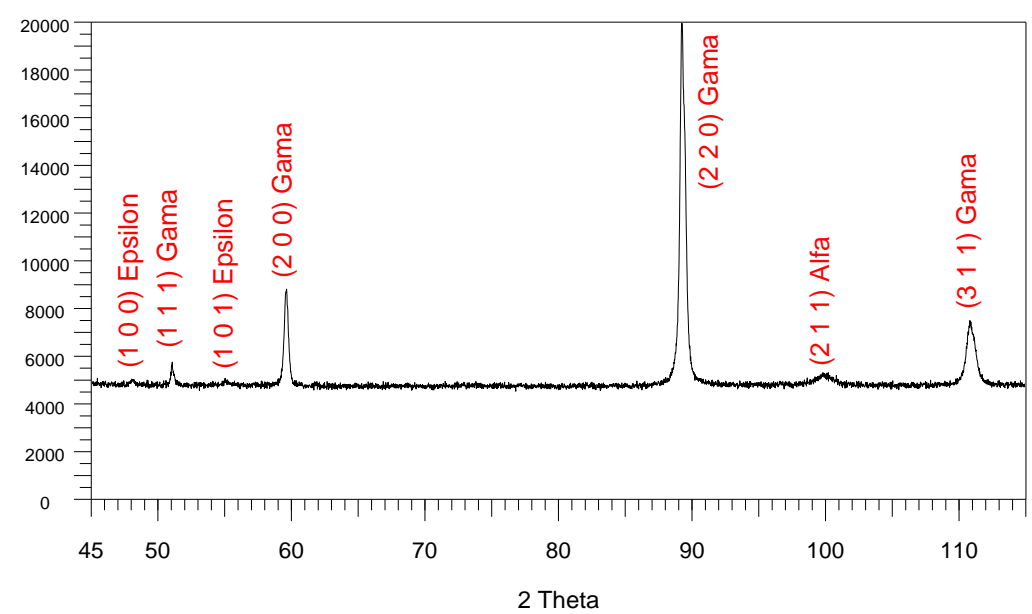

Figura 4 - Resultado da difratometria de raios-X do material laminado a quente.

De acordo com a literatura [2-7], conforme comentado anteriormente, para que se obtenha uma microestrutura totalmente austenítica é necessário controlar a adição dos elementos $\mathrm{Mn}$, Al, Si e C, de forma a manter entre $15 \mathrm{~mJ} / \mathrm{m}^{2}$ e $30 \mathrm{~mJ} / \mathrm{m}^{2}$ a EFE do

* Contribuição técnica ao $51^{\circ}$ Seminário de Laminação - Processos e Produtos Laminados e Revestidos, 28 a 31 de outubro de 2014, Foz do Iguaçu, PR, Brasil. 
material. A EFE $(\Gamma)$ de aços com elevado teor de Mn pode ser estimada através da seguinte relação, proposta por Olson e Cohen [11]:

$$
\Gamma=2 \rho \Delta G^{\gamma \rightarrow \varepsilon}+2 \sigma^{\gamma / \varepsilon},
$$

onde $\rho$ é a densidade molar dos átomos ao longo do plano $\{111\}, \Delta G$ é a energia molar de Gibbs para a transformação $\gamma \rightarrow \varepsilon$, e $\sigma$ é a energia de superfície na interface $\gamma / \varepsilon$. Aplicando-se essa relação, o valor da EFE para a liga estudada é da ordem de $12,5 \mathrm{~mJ} / \mathrm{m}^{2}$, valor que justifica a presença de martensitas $\alpha$ ' e $\varepsilon$, além da austenita, na condição de laminado a quente. Segundo a literatura [2,3,12,13], se o valor da EFE da liga estiver abaixo de $15 \mathrm{~mJ} / \mathrm{m}^{2}$, frações dessas fases podem ser formadas na matriz austenítica durante o resfriamento após a deformação a quente.

\subsection{Microestrutura do Material Laminado a Frio}

O aspecto microestrutural do material, após a etapa de laminação a frio com $60 \%$ de redução de espessura, e o difratograma de raios-X correspondente são mostrados nas figuras 5 e 6 , respectivamente. A microestrutura nessa condição é composta por grãos deformados e alongados de martensita $\alpha^{\prime}(97,7 \%)$ e de austenita $(2,3 \%)$. Essa microestrutura resulta da transformação de quase toda a austenita e de toda martensita $\varepsilon$ que existiam na condição de laminado a quente. Isso significa dizer que o mecanismo de transformação induzida por deformação plástica teve forte atuação durante a laminação a frio.

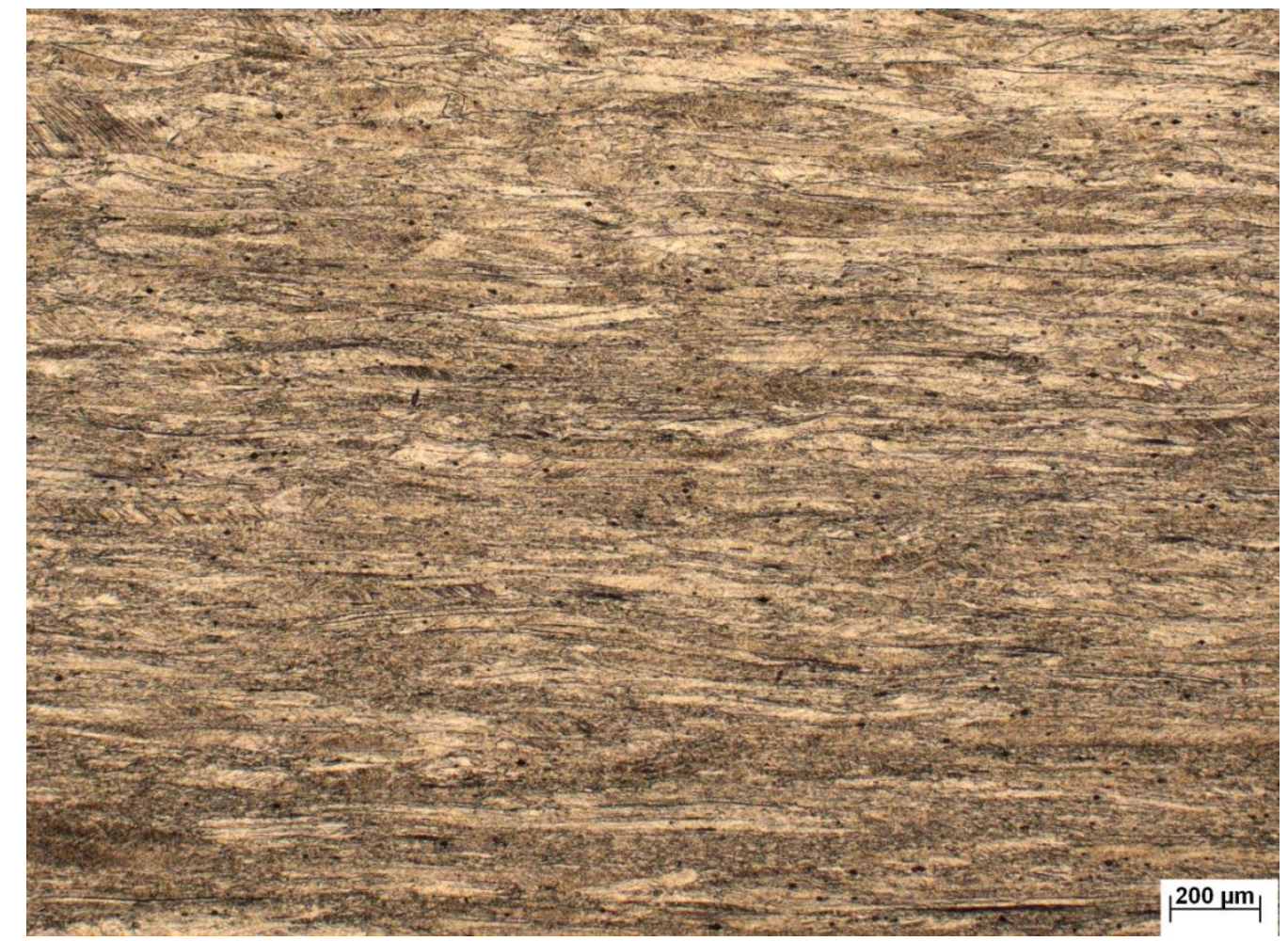

Figura 5 - Aspecto microestrutural do material na condição de laminado a frio, com $60 \%$ de redução da espessura, observado por microscopia óptica. Ampliação original 50X.

* Contribuição técnica ao $51^{\circ}$ Seminário de Laminação - Processos e Produtos Laminados e Revestidos, 28 a 31 de outubro de 2014, Foz do Iguaçu, PR, Brasil. 

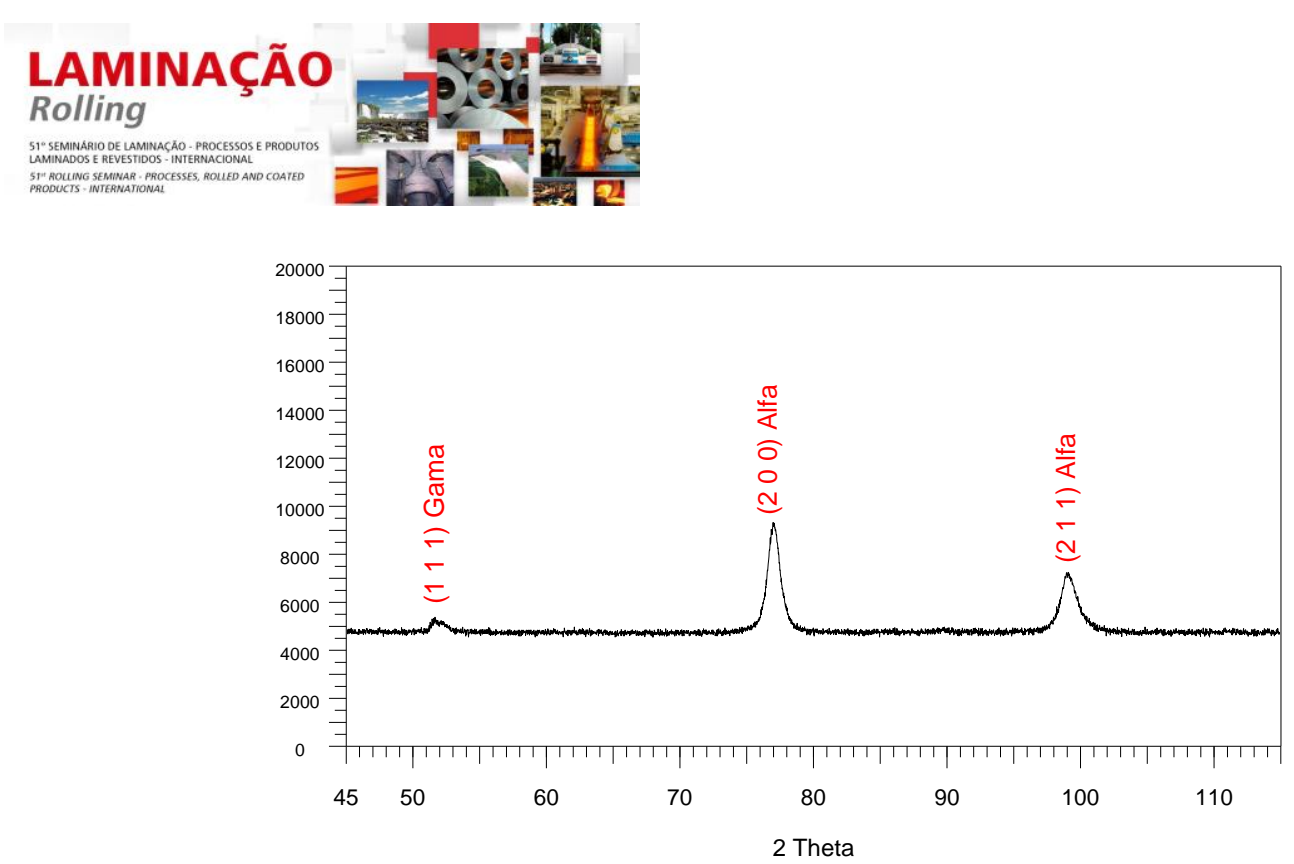

Figura 6 - Resultado da difratometria de raios-X após a etapa de laminação a frio.

\subsection{Recristalização Durante o Aquecimento Contínuo}

A curva de restauração do aço laminado a frio aquecido com taxa constante de $5^{\circ} \mathrm{C} / \mathrm{s}$, representada pela variação da dureza com a temperatura de têmpera, juntamente com a derivada da curva dilatométrica $\mathrm{d}(\Delta \mathrm{L} / \mathrm{L} 0) / \mathrm{dT}$, está mostrada na figura 7. Percebe-se que a recuperação do material teve início em torno de $400^{\circ} \mathrm{C}$, estendendo-se até próximo de $600^{\circ} \mathrm{C}$. A partir desse ponto, iniciou-se o processo de recristalização, que se completou a $820^{\circ} \mathrm{C}$. O amaciamento observado nos pontos finais da curva indica a ocorrência de crescimento de grão após a recristalização do material.

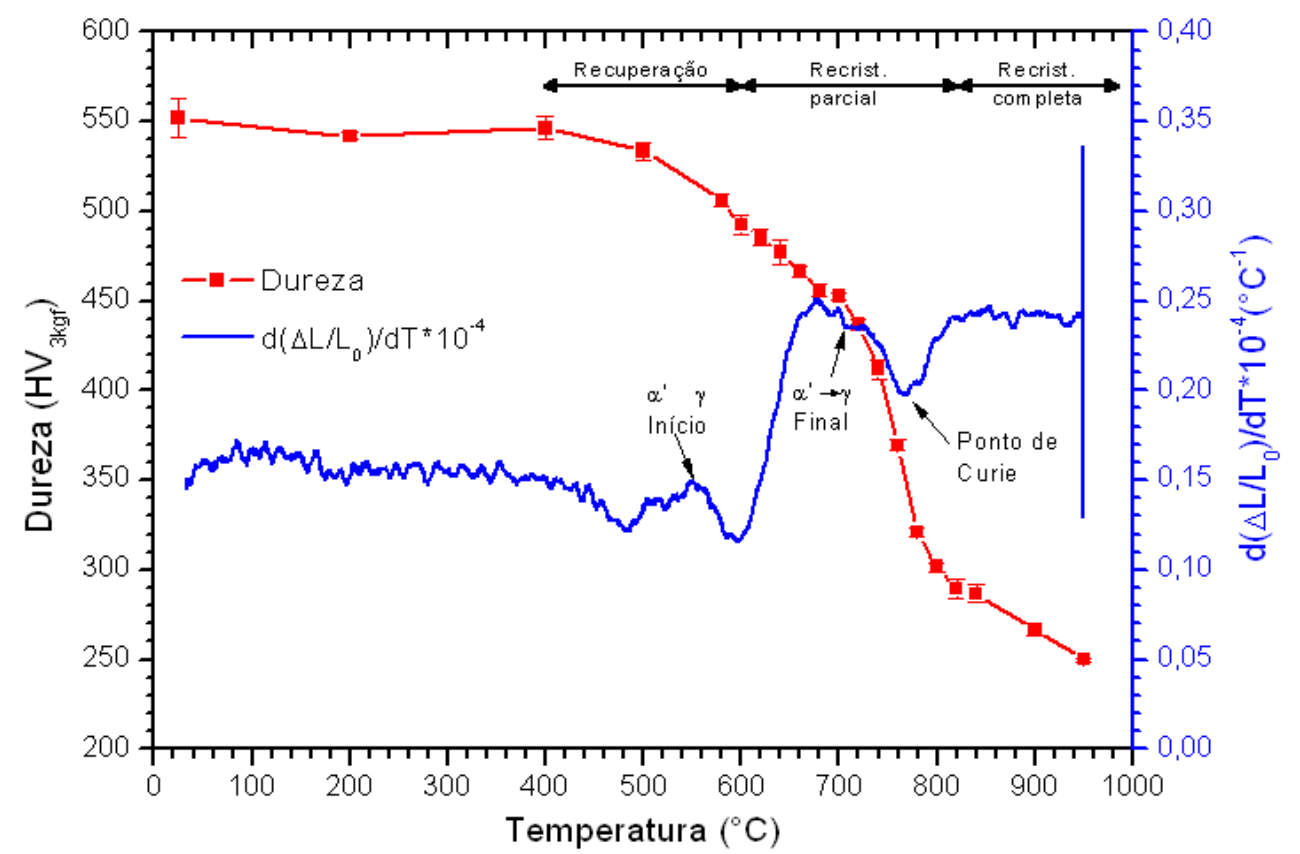

Figura 7 - Variação da dureza após têmpera e da derivada da curva dilatométrica em função da temperatura durante o aquecimento do material laminado a frio com taxa de $5^{\circ} \mathrm{C} / \mathrm{s}$.

Analisando a derivada da curva dilatométrica em função da temperatura, observa-se que o retorno da martensita $\alpha$ ' para a austenita, durante o aquecimento contínuo, ocorreu entre as temperaturas de $550^{\circ} \mathrm{C}$ e $720^{\circ} \mathrm{C}$. Continuando o aquecimento, observou-se que a transformação paramagnética do material ocorreu entre as

* Contribuição técnica ao $51^{\circ}$ Seminário de Laminação - Processos e Produtos Laminados e Revestidos, 28 a 31 de outubro de 2014, Foz do Iguaçu, PR, Brasil. 


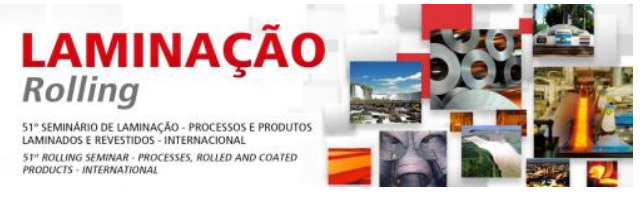

temperaturas de $720^{\circ} \mathrm{C}$ e $840^{\circ} \mathrm{C}$. Nesse intervalo, encontra-se o Ponto de Curie, que para o ferro puro é da ordem de $770^{\circ} \mathrm{C}$. Esse ponto marca a temperatura na qual a fase magnética (martensita $\alpha$ ') perde sua propriedade de magnetizar-se.

\subsection{Efeito da Temperatura de Encharque no Recozimento Contínuo}

O efeito do aumento da temperatura de encharque sobre as propriedades mecânicas do aço TWIP/TRIP é mostrado nos gráficos da figura 8. Na condição não recozida, full hard $(\mathrm{FH})$, o material exibe os maiores valores de limite de resistência (LR) e limite de escoamento (LE) e o menor alongamento. Após o recozimento, independentemente da temperatura de encharque, o limite de resistência diminuiu e 0 alongamento aumentou. Entretanto, o aumento da temperatura de encharque de $690^{\circ} \mathrm{C}$ até $810^{\circ} \mathrm{C}$ não exerceu influência significativa nos valores de $L R$, embora o LE tenha diminuído em torno de 300MPa. Esse comportamento pode ser explicado pela formação e crescimento de novos grãos de austenita no processo de recristalização do material, eliminando as maclas mecânicas formadas durante a laminação a frio e, com isso, diminuindo o valor do LE $[14,15]$.

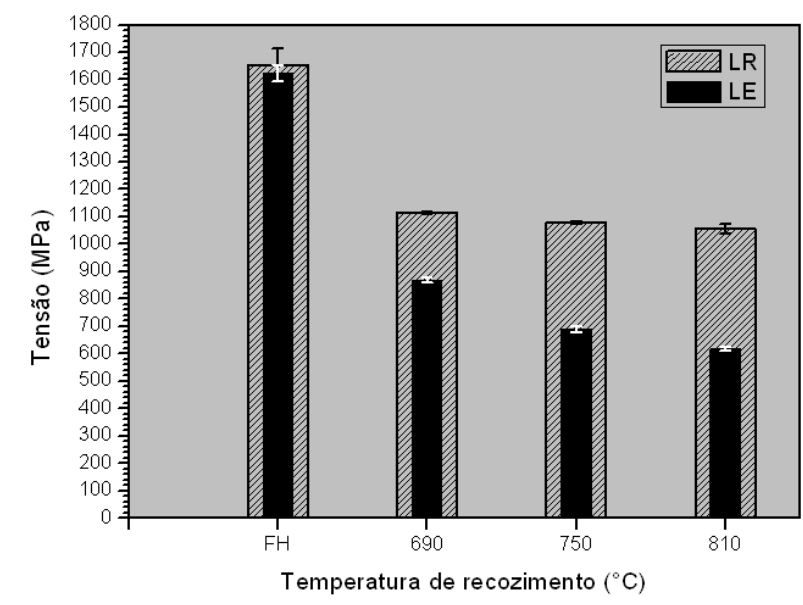

(a) LR e LE

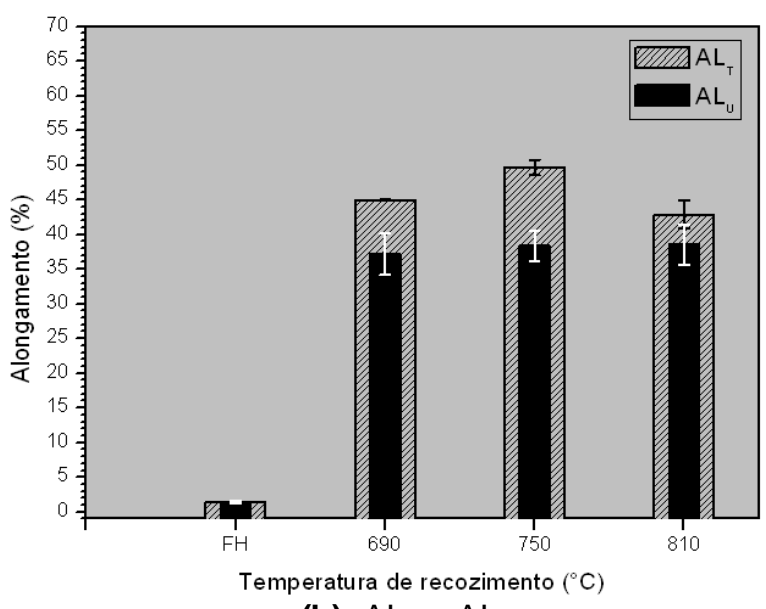

(b) ALT e ALU

Figura 8 - Valores das propriedades à tração do material nas condições full hard $(\mathrm{FH})$ e recozido nas temperaturas de $690^{\circ} \mathrm{C}, 750^{\circ} \mathrm{C}$ e $810^{\circ} \mathrm{C}$.

O aspecto microestrutural do material após as simulações dos ciclos completos de recozimento contínuo, obtido por meio dos mapas de contraste via EBSD, e a identificação de fases por difratometria de raios-X podem ser vistos na figura 9 . De maneira geral, a microestrutura do aço é bastante refinada, em função da deformação de $60 \%$ durante a laminação a frio, que foi capaz de aumentar a densidade de defeitos na rede cristalina e de transformar em martensita $\alpha^{\prime}$ quase toda a austenita presente na condição de laminado a quente. A grande quantidade de sítios para a nucleação da austenita durante o recozimento favoreceu a formação da microestrutura austenítica recozida também refinada $[16,17]$.

A quantificação de fases presentes na microestrutura do aço após o recozimento está mostrada na tabela 2. Conforme comentado anteriormente, a microestrutura do aço laminado a frio é composta majoritariamente por martensita $\alpha$ '. Embora boa parte dessa fase tenha retornado para austenita durante o recozimento realizado a $690^{\circ} \mathrm{C}$, como se vê na tabela 2 , essa temperatura não foi suficientemente alta para promover a recristalização completa do material, como indica a microestrutura heterogênea observada na figura 9 (a). Esse resultado está em acordo com as

* Contribuição técnica ao $51^{\circ}$ Seminário de Laminação - Processos e Produtos Laminados e Revestidos, 28 a 31 de outubro de 2014, Foz do Iguaçu, PR, Brasil. 


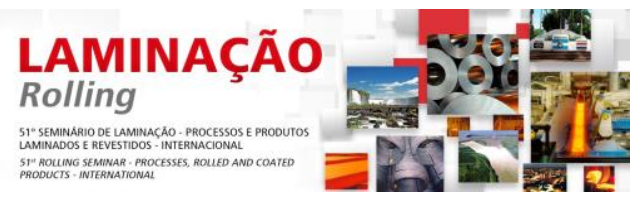

curvas da figura 7 , que mostram que na temperatura de $690^{\circ} \mathrm{C}$ a recristalização e a reversão da martensita $\alpha^{\prime}$ para austenita ainda não estão completas.
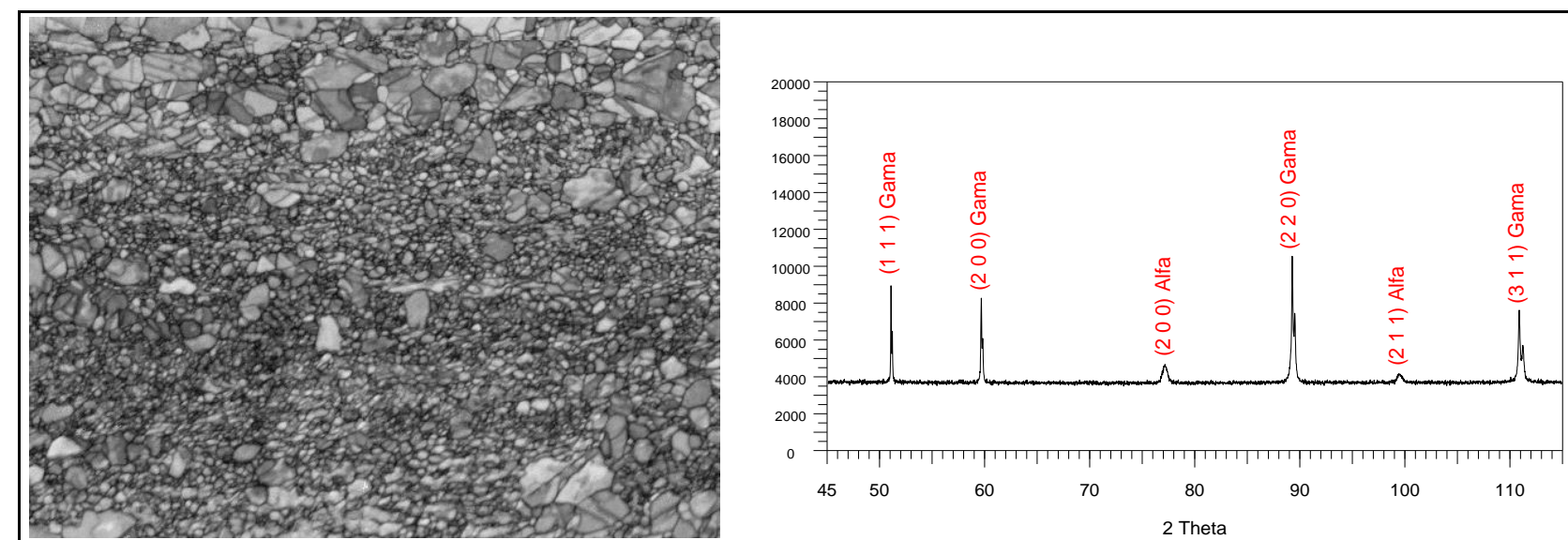

(a) Temperatura de recozimento $-690^{\circ} \mathrm{C}$
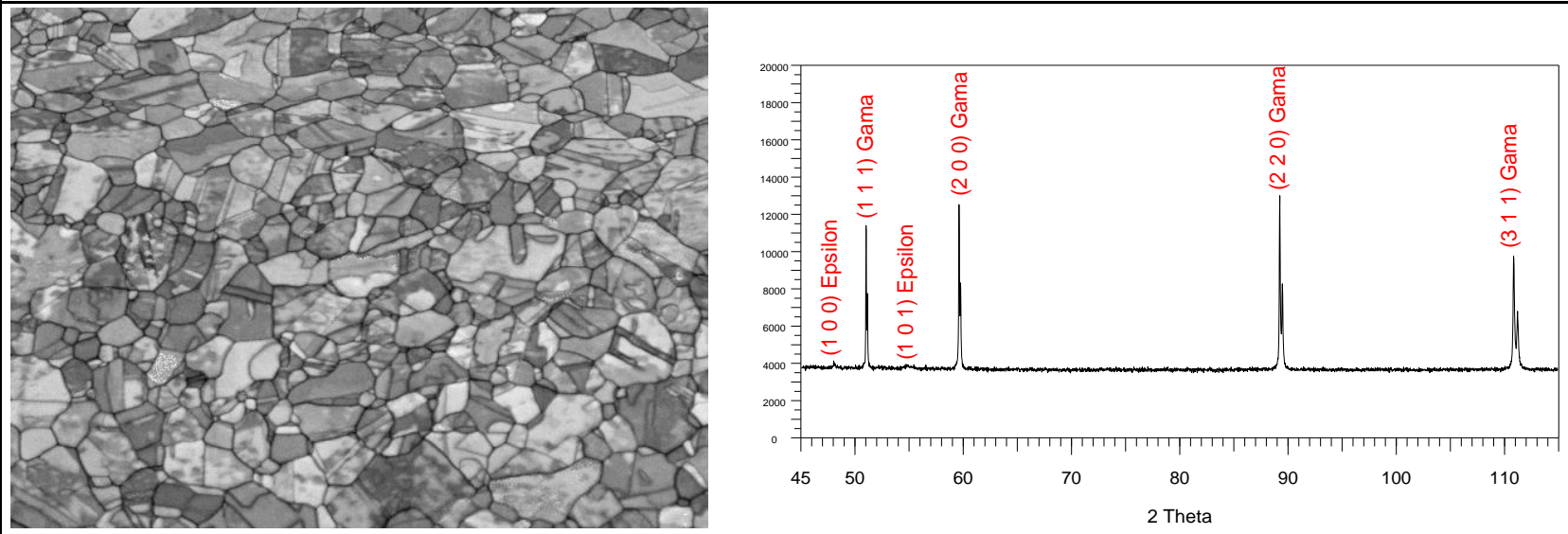

(b) Temperatura de recozimento $-750^{\circ} \mathrm{C}$
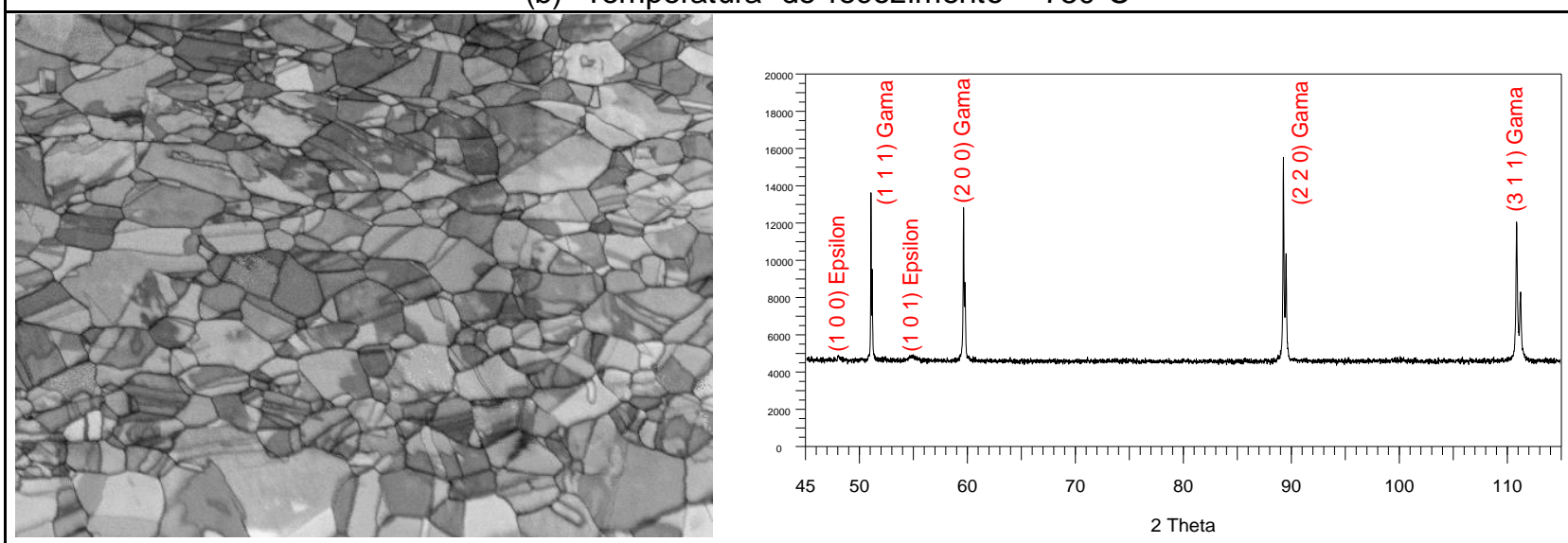

(c) Temperatura de recozimento $-810^{\circ} \mathrm{C}$

Figura 9 - Aspecto microestrutural das amostras submetidas à simulação do recozimento contínuo nas temperaturas de $690^{\circ} \mathrm{C}, 750^{\circ} \mathrm{C}$ e $810^{\circ} \mathrm{C}$ e os respectivos difratogramas de raios-X (DRX).

Após o recozimento com encharque a $750^{\circ} \mathrm{C}$, já se observou a recristalização completa da microestrutura e o retorno total da fase martensita $\alpha$ ' presente no material laminado a frio para a fase austenítica, figura 9 (b). Essa transformação resulta num aumento significativo da fração volumétrica de austenita em relação ao material recozido a $690^{\circ} \mathrm{C}$. Além disso, a partir de $750^{\circ} \mathrm{C}$ observa-se a presença da fase martensita $\varepsilon$ nos respectivos difratogramas, provavelmente formada durante a etapa de resfriamento do recozimento contínuo. Isso é possível, já que, de acordo

* Contribuição técnica ao $51^{\circ}$ Seminário de Laminação - Processos e Produtos Laminados e Revestidos, 28 a 31 de outubro de 2014, Foz do Iguaçu, PR, Brasil. 


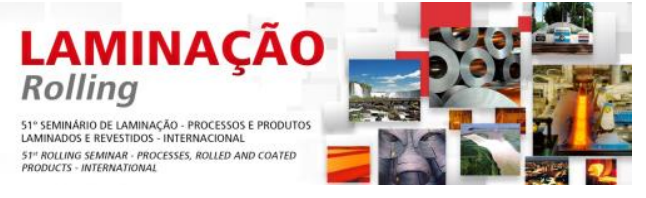

com dados da literatura [18], a temperatura de início de transformação da martensita $\varepsilon$ (Mss) para a liga estudada é de $172^{\circ} \mathrm{C}$. Quando a temperatura de encharque passou de $750^{\circ} \mathrm{C}$ para $810^{\circ} \mathrm{C}$, não foram observadas grandes diferenças microestruturais no material. De qualquer modo, nessas duas temperaturas foi formada uma microestrutura mais homogênea, com a presença de maclas de recozimento no interior dos grãos austeníticos.

Tabela 2 - Resultados da análise quantitativa dos constituintes formados na microestrutura do aço após as simulações dos ciclos térmicos de recozimento contínuo.

\begin{tabular}{cccc}
\hline \multirow{2}{*}{$\begin{array}{c}\text { Temperatura de } \\
\text { encharque }\end{array}$} & \multicolumn{3}{c}{ Fração volumétrica (\%) } \\
\cline { 2 - 4 } & $\left({ }^{\circ} \mathrm{C}\right)$ & $\alpha^{\prime}$ & $\varepsilon$ \\
\hline 690 & 83,5 & 16,5 & 0,0 \\
\hline 750 & 98,5 & 0,0 & 1,5 \\
\hline 810 & 98,1 & 0,0 & 1,9 \\
\hline
\end{tabular}

\section{CONCLUSÕES}

Verificou-se que a microestrutura do aço laminado a quente é constituída em sua grande parte por austenita, além de martensita $\varepsilon$ e $\alpha$ '. Após a etapa de laminação a frio, a microestrutura foi composta majoritariamente por martensita $\alpha$, indicando que o mecanismo de transformação induzida por deformação plástica teve forte atuação durante a laminação a frio.

Durante o aquecimento do material deformado a frio, o processo de recuperação teve inicio em torno de $400^{\circ} \mathrm{C}$ e se estendeu até próximo de $600^{\circ} \mathrm{C}$. A partir desse ponto, iniciou-se o processo de recristalização, que se completou em $820^{\circ} \mathrm{C}$. O retorno da martensita $\alpha$ para a austenita ocorreu entre as temperaturas de $520^{\circ} \mathrm{C}$ e $720^{\circ} \mathrm{C}$.

$\mathrm{O}$ aumento da temperatura de recozimento de $690^{\circ} \mathrm{C}$ para $810^{\circ} \mathrm{C}$ não exerceu influência significativa no limite de resistência do material, mas resultou em uma redução em torno de $300 \mathrm{MPa}$ no limite de escoamento. Esse comportamento pode ser explicado pela dissolução da fase martensita $\alpha^{\prime}$ e pela formação de novos grãos de austenita durante o processo de recristalização do material.

O recozimento realizado na temperatura de $690^{\circ} \mathrm{C}$ não foi suficiente para promover a recristalização completa da microestrutura, composta por austenita de granulação mista e martensita $\alpha$ '. A partir da temperatura de recozimento de $750^{\circ} \mathrm{C}$ toda a martensita $\alpha$ ' presente no material laminado a frio retornou para a fase austenítica, cujos grãos apresentaram maclas de recozimento. Além da austenita, o aço recozido a $750^{\circ} \mathrm{C}$ e $810^{\circ} \mathrm{C}$ também apresentou frações de martensita $\varepsilon$, formada provavelmente durante o resfriamento do mesmo no ciclo de recozimento contínuo.

\section{Agradecimentos}

Os autores agradecem a CAPES/PROEX pelo apoio financeiro à condução do projeto de pesquisa e a Usiminas pela permissão de publicação do presente trabalho. 
